\title{
Customized Online Promotions: Moderating Effect Of Promotion Type On Deal Value, Perceived Fairness, And Purchase Intent
}

Patrali Chatterjee, Montclair State University, USA

John McGinnis, Montclair State University, USA

\begin{abstract}
This paper investigated whether consumers differ in their perceptions of deal value, fairness and purchase intentions when presented with individually targeted (or customized) promotions versus universal promotions offered to all consumers at online retail websites. It was found that customized offers lead to significantly higher purchase intent compared to universal offers. Perceived fairness differed significantly across promotion types (free shipping, \$ off and temporary reduced price) based on whether they were customized to the consumer or offered universally. Implications for designing customized online promotions are offered.
\end{abstract}

Keywords: customized promotions; deal value; perceived fairness; price discrimination;

\section{INTRODUCTION}

C)

he exponential growth and technological development of the Web and the Internet has fueled the enthusiasm towards developing customer-responsive promotions. In 2009 alone, online promotions are projected to account for $\$ 1.6$ billion out of $\$ 25.7$ billion in total US online ad spending (Hallerman 2008). The initial enthusiasm for online promotions was the lure of addressability and mass customization. The ability to track click behavior over time and infer what drives a targeted consumer (or a cookie ID) to purchase, coupled with the potential of developing promotions of the right kind, offered at the right instant, to the right customer can be the key to retailing success. However, effective customization of promotions requires consumers to register online and implicitly allow the online retailer to monitor their online activity in order to avail promotions. Little is known how privacy concerns impact consumer perceptions of customized price promotions and different types of promotions.

Prior research in marketing has firmly established that consumers differ in their perceptions of promotion offers based on the framing of the promotion (Suri, Swaminathan, and Monroe 2004). Frames investigated were restrictions on promotion availability and promotion type (Inman, Peter, and Raghubir 1997). In stores, marketers use physical possession of coupons to restrict who gets the price savings, a strategy of price discrimination because only price-sensitive buyers are willing to expend efforts to collect and redeem coupons (Narasimhan 1984). Coupon promotions were found to have significantly higher perceptions of deal value compared to reduced price promotions available to all consumers. Universal promotions or promotions offered to all consumers erode brand equity, increase price sensitivity and have lower effectiveness compared to coupons (Suri, Swaminathan, and Monroe 2004).

In the online marketplace, physical possession of coupons cannot be used to implement targeting restrictions. Online promotions are typically implemented through the use of promotion or offer codes or links to specific pages at the website with the promotional offer. The proliferation and easy access to coupon repository websites that provide searchable access to promotion codes and promotion page URLs has made over-redemption of restricted promotions a cause of concern and defeats the purpose of price discrimination. Restricting access to promotions online requires targeting, identifying and tracking consumer click behavior (or their online identities) at the individual level. Anecdotal evidence suggests that some retailers have realized gains from such customized 
promotions to a limited extent, but for many consumer acceptance and redemption of customized online promotions is fraught with mistrust and technical challenges. Many consumers are concerned that web monitoring involved in online targeting and customization invades their privacy (Fox et al. 2000). So it is important to examine how consumer privacy concerns impact or interact with perceived transaction benefits from using an online promotion.

This research investigated whether consumers differ in their perception and use of sales promotions if they are offered universally or customized (i.e., available only when consumers register or log in). There is considerable research indicating that different implementations or framing of the same retail price reduction (dollar off, or temporary price reductions) can change consumers' perception of the promotion offer and purchase decisions. Further, free shipping has emerged as a popular online promotion but has not been examined extensively in the pricing literature, since it is not relevant in store-based shopping. Hence this study examines whether consumer perceptions of deal value, fairness and purchase intent differs for different promotion types based on whether promotions are customized or universally offered.

\section{CONCEPTUAL FRAMEWORK AND HYPOTHESES}

The customization of a promotion offer can be viewed as a restriction increasing the perception of exclusivity and deal value for the promotion recipient. Research by Feinberg, Krishna, and Zhang (2002) provides evidence of a betrayal effect whereby loyal consumers of a brand provide less favorable preferences for that brand when they were excluded from a targeted deal offered only to competitors' customers. Equity frameworks (Bolton and Ockenfels 2000) presume that individuals will engage in inter-personal comparisons that factor not only the outcomes one receives (non-social utility) but also how such outcomes compare to those accrued by others (social utility). When consumers react to marketing offers with the goal of maximizing personal welfare (i.e., they are selfregarding), the receipt of an exclusive deal leads to advantageous inequity that enhances evaluations of the targeted discount among deal recipients (cf. Loewenstein, Thompson, and Bazerman 1989). Further, active participation of customers in specifying their preferences is expected to make the fit between the offer and customers' preferences more transparent and lead to higher offer attractiveness. Hence,

H1: Perceived deal value of customized promotions will be higher than that of universal promotions.

Simonson (2005) suggests the "customized" label can positively affect perceived fit, assuming that the customer trusts the marketer. Inferred motive for the promotion is one of the key antecedents of trust (Campbell 1999). An inferred motive for a customized promotion restricted to an individual may imply a retailer's willingness to forgo profits (a positive motive) in order to build or strengthen a relationship with the consumer leading to perceptions of fairness. However, concerns of privacy and exploitative use of web monitoring have been consistently borne out in numerous surveys. Customized offers may lead to perceptions of "being singled out" and attempts to manipulate and persuade (Friestad and Wright 1994) increasing perceived unfairness. The experimental design was not designed for prior or repeated consumer-retailer experiences hence it is not expected that subjects would develop experience-based trust. In contrast, retailers using universal promotions treat all buyers equally and thus the issue of lateral unfairness does not arise. Hence it is hypothesized that,

H2: Perceived fairness will be lower for customized promotions than for universal promotions.

Since customization requires efforts in specifying consumer preferences and provide identifying information, consumers may perceive an advantageous price equity and just financial exchange for providing personal information. They may perceive a prerogative of paying a "special" lower price and the process of participating in the customization may lead them to feel smart and competent as shoppers (Schindler, Morrin and Bechwati 2005) than when promotions are offered to all customers. Further, since customized promotions are not displayed on comparison shopping agents, promotions offered after login at a retailer site can lead to a "pleasant surprise" effect (Heilman, Nakamoto and Rao 2002), the unexpected gain can elevate consumers' moods thus increasing purchase intentions.

H3: Purchase intentions will be higher for customized promotions than for universal promotions. 
Moderating Effect of Promotion Type: Prior research on promotions suggests that coupons have higher deal value and purchase intent relative to discounted price promotions (Suri, Swaminathan, and Monroe 2004). Shipping charges are considered a disutility in online shopping and consumers attribute profit motives (not just covering cost) to the retailer. Free shipping promotions can reduce perceptions of unfairness but not increase deal value since base price of product remains the same. If customized promotions are perceived to be more attractive, exclusive or better matched to their preferences compared to universal promotions (i.e., H1 is supported) it should amplify the perceived value for promotion types that reduce the base price but not that of free shipping. Hence it is hypothesized that,

H4a: Perceived deal value of \$off and discounted price will be higher when promotions are customized than when universally offered but not significantly differ for free shipping or no promotion.

In the absence of experience-based trust (due to the experimental context), cue-based trust or surface credibility may play an important role. Cue-based trust is defined as trust generated based on an individual's initial encounter with the stimulus (retailer website). It involves consumers' beliefs that his or her vulnerabilities will not be exploited (Dholakia and Sternthal 1977). Cue-based trust is based on informational cues provided by the seller and is important in building consumer trust in an online shopping environment especially for sellers that lack traditional cues like national reputation and impressive size. The literature on signaling and asymmetric information suggests that actions such as money-back guarantees and price protection serve as risk relievers (Akaah and Korgaonkar 1988). Further, Simonson (2005) proposes that consumers are likely to rely on cues for assessing the fit of a customized offer with their preferences in the presence of consumer trust. Hence free shipping may engender higher levels of trust compared to \$off or temporary price reductions. Further, this effect will be higher when promotions are customized compared to universally offered. Hence it is hypothesized that:

H4b: Perceived fairness will be higher for free shipping compared to $\$$ off or discounted and this difference will be higher for customized promotions compared to universal promotions.

Since perceived deal value of promotion and fairness influences purchase intention and hypotheses $\mathrm{H} 4 \mathrm{a}$ and $\mathrm{H} 4 \mathrm{~b}$ suggest contrasting impacts for the three promotion types, this study did not attempt to predict which of these effects would dominate, hence no hypotheses for purchase intention are specified.

\section{EXPERIMENTAL METHOD AND MEASURES}

Design: A $2 \times 4$ between-subject design was used to examine the effect of promotion customization ( 2 conditions universal offer, customized offer) and promotion type (4 conditions -free shipping, $\$$ off, reduced price and no promotion) at an experimental website. To maintain task interest and involvement, students considered the purchase of a particular product (digital camera), at a fictitious retailer to control for the possible confounding effects due to brand or retailer reputation. Table 1 shows the stimuli conditions:

Table 1. Experimental conditions and stimuli

\begin{tabular}{|c|c|c|c|c|}
\hline & $\$$ off & Discounted price & Free shipping & No promotion \\
\hline Customized & $\begin{array}{l}\text { (name), this } \$ \text { off offer is } \\
\text { for you: }\end{array}$ & $\begin{array}{l}\text { (name), this reduced } \\
\text { price offer is for you: }\end{array}$ & $\begin{array}{l}\text { (name), this free } \\
\text { shipping offer is for you: }\end{array}$ & $\begin{array}{l}\text { (name), this price is for } \\
\text { you: }\end{array}$ \\
\hline Universal & $\begin{array}{l}\text { Price: } \$ 100 \\
\text { Promotion: } \$ 10 \\
\text { S/H: } \$ 20\end{array}$ & $\begin{array}{l}\text { Price: } \$ 90 \\
\text { S/H: } \$ 20\end{array}$ & $\begin{array}{l}\text { Price: } \$ 110 \\
\text { Promotion: free shipping }\end{array}$ & $\begin{array}{l}\text { Price: } \$ 100 \\
\text { S/H: } \$ 20\end{array}$ \\
\hline
\end{tabular}

Eight versions of the experimental website were created and hosted locally to allow collection of clickstream data. The three customized promotional offers did not appear on product description pages, instead they were displayed on product description cart pages after the consumer logged in. The customized no-promotion version did not have any promotion offer and simply advised respondents to log in. Pre- and post experiment questionnaires were integrated so responses could be electronically recorded. 
Sample. Three hundred fifty-two (352) undergraduate marketing students at a northeastern university, with about equal number of males and females were randomly assigned to the treatment conditions. Participation was requested for 45 minutes for course credit. Responses for 28 students who agreed to participate but did not come for the main study were discarded.

Procedure. Subjects reported at a computer lab and were allocated to specific terminals. All subjects read the same cover story - the researcher was studying usability issues at websites. Respondents in the universal promotion condition were instructed to answer a questionnaire on familiarity and expertise with using the Internet, online purchasing history and demographic questions. After submitting their questionnaire they went to the experimental website with appropriate promotion offers to begin the main experiment. Respondents in the customized site condition were instructed to register for access to the retailer's website using their email username and password. Subjects then answered the Internet familiarity and purchase history questionnaire similar to the universal condition and asked to log out. These subjects then started the main experiment and were asked to login before browsing through the site. The appropriate promotion offer was displayed on pages after login.

Respondents were allowed to browse through product descriptions, take as much or little time as needed and add products to their shopping cart and checkout. After submitting the checkout page respondents were taken to a webpage to collect dependent measures and responses to manipulation check questions. Subjects could click on an exit hyperlink provided on each page, fill out the questionnaire for dependent measures and leave. All respondents were thanked for their participation and debriefed.

Dependent Variables: Behavioral dependent measures - checkout or abandon cart were collected from clickstream data. Perceptual measures were collected through surveys at the end of experiment. Perceived fairness was rated on a bipolar adjective scale ranging from 1 - very fair to 7 very unfair (Campbell 1999). Perceived deal value was measured using a three-item, seven-point semantic differential scale bad deal- good deal, worthless-valuable, and unattractive to me- attractive to me $(\mathrm{r}=0.89, \mathrm{p}<0.001)$ (Grewal et al. 1998). Purchase intention was measured using a seven-point semantic differential scale anchored at "definitely not-definitely will."

Manipulation Checks. A pretest was conducted with 33 students not participating in the main study to see if the four brands of products were perceived differently. In response to an open-ended question at the end of the survey respondents mentioned that differences were "minor", "cosmetic". To test the universal vs. customizable versions of websites the mean score of responses to questions on identification, adaptability and closeness (De Wulf et al. 2001) of website were utilized. The difference in score for customized vs. universal versions were significant across the promotion-type versions 6.9 (s.d.=2.9) vs. $3.7(\mathrm{~s} . \mathrm{d} .=1.2), \mathrm{t}=3.12, \mathrm{p}<0.001$, indicating that the customization manipulation was successful. Almost all subjects had purchased from online stores in the last 6 months. Respondents did not significantly differ in their familiarity with Internet or digital camera use across conditions.

\section{RESULTS}

A two-way multivariate analysis of variance (MANOVA) was conducted. Since it was expected that the dependent variables would be correlated, MANOVA was utilized instead of several univariate ANOVAs to test the hypotheses and avoid inflating Type I error. Univariate (ANOVA) follow-up analyses were conducted where appropriate. Fratios were evaluated with an alpha level of 0.05 for all main effects and post-hoc comparisons. Effect size, or strength of relationship, associated with univariate analyses was reported using partial Eta squared $\left(\eta_{p}^{2}\right)$. Detailed MANOVA results are available from the authors; Table 1 presents results for the effects that were found significant.

Customization by promotion type (2x4) MANOVA shows a borderline significant main effect for offer customization, $\mathrm{F}(9,3386)=3.03, \mathrm{p}=0.056\left(\mathrm{R}^{2}=0.35\right)$ and for promotion type, $\mathrm{F}(9,3386)=4.75, \mathrm{p}=0.005\left(\mathrm{R}^{2}=0.31\right)$. Follow-up ANOVAs and mean comparisons revealed a significant difference between offer customization for purchase intent, $F(3,1387)=8.44, p<0.025\left(\eta_{p}^{2}=0.24\right)$ and perceived deal value $\left(\eta_{p}^{2}=0.009\right)$, but not for perceived fairness $\left(\eta_{p}^{2}=0.007\right)$. Follow-up univariate ANOVAs and mean comparisons for the promotion type main effect are explained separately for each perceptual measure. 
Table 1. Multivariate and Univariate Effects

\begin{tabular}{|c|c|c|c|c|}
\hline \multirow[b]{2}{*}{ Source } & \multicolumn{2}{|c|}{ Multivariate } & \multirow{2}{*}{$\begin{array}{c}\text { Univariate } \\
\mathbf{F} \\
\end{array}$} & \multirow{2}{*}{$\begin{array}{c}\text { Hypotheses test } \\
\text { results }\end{array}$} \\
\hline & $\mathbf{F}$ & df $\left(v_{1}, v_{2}\right)$ & & \\
\hline \multicolumn{4}{|c|}{ Main effects } & \multirow{8}{*}{$\begin{array}{l}\text { H3 supported } \\
\text { H1 supported }\end{array}$} \\
\hline Customization & $3.03 *$ & 9,2386 & & \\
\hline Purchase intent & & 1,1387 & $2.47 *$ & \\
\hline Perceived deal value & & 1,1387 & $3.5 * *$ & \\
\hline Promotion type & $4.75 * *$ & 9,3386 & & \\
\hline Perceived fairness & & 3,1387 & $2.67 *$ & \\
\hline Purchase intent & & 3,1387 & $8.44 * *$ & \\
\hline & action effe & & & \\
\hline Customization $*$ Promotion type & $4.12 * *$ & 9,3386 & & \\
\hline Perceived deal value & & 3,1387 & 1.2 & H4a rejected \\
\hline Perceived fairness & & 3,1387 & $3.94 * *$ & H4b supported \\
\hline Purchase intent & & 3,1387 & 0.77 & \\
\hline
\end{tabular}

$* \mathrm{p}<0.05, * * \mathrm{p}<0.01$

Perceived Deal Value of Promotion: The mean comparisons show significant differences between universal (M=6.1, s.d. 0.8$)$ and customization $(\mathrm{M}=4.2$, s.d. 2.1$)$ conditions $\left(\mathrm{p}<0.05, \eta_{\mathrm{p}}^{2}=0.03\right)$ thus $H 1$ is supported. These results suggest that respondents perceive customized promotions as good deals but not universal promotions even though the objective saving is the same in both conditions.

Perceived Fairness: Table 1 indicates a significant ANOVA for perceived fairness across promotion type ( $\mathrm{p}=0.001$, $\eta_{\mathrm{p}}^{2}=0.19$ ), but not for customization. Thus $H 2$ is not supported. Mean comparisons revealed a significant difference between no promotion ( $\mathrm{M}=4.6$, s.d. 0.5) and free shipping ( $\mathrm{M}=5.9$, s.d. 1.1) $\left(\mathrm{p}=0.04, \eta_{\mathrm{p}}^{2}=0.09\right)$, between free shipping and discounted price $(\mathrm{M}=3.4$, s.d. $1.5, \mathrm{p}=0.005)$, and between free shipping and $\$$ off $(\mathrm{M}=2.2$, s.d. 0.8), $\left(\mathrm{p}=0.001, \eta_{\mathrm{p}}^{2}=0.15\right)$. These results suggest shipping charges drive unfairness perceptions, and offering promotions while charging for shipping is perceived as more unfair than not offering promotions at all.

Purchase Intent: Table 1 indicates that the mean purchase intent score in customized promotion was 5.6 (s.d. 1.2), while in the universal promotion it was 2.9 (s.d. 2.8), hence $H 3$ is supported. There is also a significant main effect of promotion type for purchase intention $(\mathrm{p}=0.002)$. Mean comparisons revealed a significant difference between free shipping and no promotion $(\mathrm{p}=0.009)$, but not between $\$$-off and no promotion $(\mathrm{p}=0.69)$, nor between free shipping and discounted price $(\mathrm{p}=0.41)$. These results suggest that offering dollars off promotion sends negative signals, but free shipping or discounted price doesn't.

Interactions: A significant customization x promotion type multivariate interaction effect was found but it was significant only for perceived fairness, thus rejecting $H 4 a$ but supporting $H 4 b$. Mean comparisons suggest that consumer perceptions of fairness for free shipping and $\$$ off in the customized condition are significantly higher and lower respectively compared to the universal condition, thus supporting $H 4 b$. Perceived fairness for no promotion and temporary price reduction are insignificantly lower and higher in the universal offer condition compared to customization condition. This may suggest that consumers may be wary of manipulation efforts directed to them through customized promotions, however free shipping offers are perceived to be less threatening compared to \$off or reduced price offers. Further, asymmetry in gains and losses may suggest that if free shipping cannot be offered, a retailer using customized promotions may be better off not offering any promotions at all.

\section{DISCUSSION AND FUTURE RESEARCH}

This study has a number of important implications for understanding how consumers perceive price promotions at online retail websites. Customized promotions may lead to higher perceived deal value and purchase intentions compared to promotions offered to all consumers. Further, contrary to popular belief regarding privacy concerns, the use of customized promotions does not lead to higher unfairness perceptions. The significant customization by promotion type interaction for perceived fairness suggests that customized promotions are not perceived to be unfair compared to universal promotions rather it is the type of promotion used in customized 
promotion that may lead to unfairness perceptions. This indicates that certain types of customized promotions may have a net positive impact on increasing purchase conversion at online retail sites which may not work if made available to all consumers (universal). However, most subjects in this experimental study are university students who are familiar with use of the Web and most $(61 \%)$ have purchased online in the prior 6-month period. They expect to be rewarded with promotion offers in exchange for the information they provide for customization. Negative impact of privacy concerns and reactance may play a bigger role among the general population, especially those who are less skilled or intimidated by the technology. Further, the experimental stimuli operationalized customization by embedding promotion offers within the product description pages. If promotion offers were served through pop-up ads, feelings of intrusion, irritation and annoyance may have accentuated consumer concerns about web monitoring leading to increased perceptions of unfairness. Future research should investigate the mode of presentation of promotion offers and technical competence in perception of universal and customized offers.

There is a differential impact of free shipping as a promotion type on consumer perceptions. In general, free shipping is perceived to be as good or superior to all other promotion types in perceptions of fairness, perceived promotion value and purchase intent irrespective of whether promotions are customized or offered to all consumers. For equivalent dollar savings, and where shipping charges are communicated, free shipping represents the most attractive promotion type. There is evidence of this finding on the web, most retailers offer free shipping above a threshold order size. In certain product categories, free shipping above a minimum purchase is instituted as standard policy by all major firms. \$-off promotion performs better than reduced price as has been demonstrated in storebased promotions (Chen et al. 1998). However this holds true if promotions are universally offered but not when promotions are customized. This research focused on promotion-type effects; however, future research can be directed towards investigating if this effect is robust across various levels of the product base price and depth of discount. Further if shipping prices are unknown or offer lower or higher savings in dollars compared to other promotion types free shipping may not be as critical as found here and thus suggest another interesting avenue for future research.

\section{RECOMMENDATIONS FOR RETAILERS}

- $\quad$ Customized promotions enhance on-line shoppers' perception of deal value.

- Customized promotions increase on-line shoppers' purchase intention.

- $\quad$ On-line shoppers perceive lower prices derived from eliminating shipping charges as a fairer business practice than lower prices derived from a combination of discounts or \$-off offers that include shipping charges.

- $\quad$ Free shipping increases on-line shoppers purchase intent.

\section{BIBLIOGRAPHY}

1. Akaah, Ishmael P. and Korgaonkar, Pradeep K. (1988), "A Conjoint Investigation of the Relative Importance of Risk Relievers in Direct Marketing," Journal of Advertising Research, 28, August/September, 38-44.

2. Bolton, Gary E. and Axel Ockenfels (2000), "ERC: A Theory of Equity, Reciprocity, and Competition," American Economic Review, 90 (March), 166-193.

3. Campbell, Margaret C. (1999), "Perceptions of Price Unfairness: Antecedents and Consequences," Journal of Marketing Research, 36 (May), 187-99.

4. De Wulf K., Odekerken-Schröder G. \& Iacobucci D (2001), "Investments in Consumer Relationships: A Cross-Industry Exploration," Journal of Marketing, 65, October, 33-50.

5. Dholakia, R.R and Sternthal, B. (1977), "Highly Credible Sources: Persuasive Facilitators or Persuasive Liabilities?" Journal of Consumer Research, 3, March, 223-232.

6. Fox, Susannah, John Horrigan, Amanda Lenhart, Tom Spooner, and Cornelia Carter (2000), "Trust and Privacy Online: Why Americans Want to Rewrite the Rules," The Pew Internet \& American Life Project, The Pew Research Center, Washington, DC, available at www.pewinternet.org/reports/toc.asp?Report=19.

7. Friestad, M., \& Wright, P (1994), “The persuasion knowledge model: How people cope with persuasion attempts," Journal of Consumer Research, 21, 1-31. 
8. Feinberg, Fred M., Aradhna Krishna and Z. John Zhang (2002), "Do We Care What Others Get? A

Behaviorist Approach to Targeted Promotions," Journal of Marketing Research, 39 (August), 277-291.

9. Grewal, D., Monroe, K.B., \& Krishnan, R. (1998). The Effects of Price-Comparison Advertising on Perceptions of Acquisition Value, Transaction Value, and Behavioral Intentions, Journal of Marketing, 62, 46-59.

10. Hallerman, David (2008), "What Lies Ahead in the New Year?" E-Marketer. http://www.emarketer.com/Articles/1006813

11. Heilman, Carrie M., Kent Nakamoto and Ambar Rao (2002), "Pleasant Surprises: Consumer Response to Unexpected In-store Promotions," Journal of Marketing Research, 39 (May), 242-251.

12. Inman, J. Jeffrey, Anil C. Peter and Priya Raghubir (1997), "Framing the Deal: The Role of Restrictions in Accentuating Deal Value," Journal of Consumer Research, 24 (June), 68-79.

13. Loewenstein, George F., Leigh Thompson, and Max H. Bazerman (1989), "Social Utility and Decision Making in Interpersonal Contexts," Journal of Personality and Social Psychology, 57 (3), 426-441.

14. Narasimhan, C. (1984), "A price discrimination theory of coupons," Marketing Science, 3 (2), pp. 128-147.

15. Suri, Rajneesh, Srinivasan Swaminathan, Kent B. Monroe (2004), "Price communications in online and print coupons: An empirical investigation," Journal of Interactive Marketing, 18(8), 74-86.

16. Schindler, Robert, Maureen Morrin and Nada Nasr Bechwati (2005), "Shipping Charges and Shipping Charge Skepticism: Implications for Direct Marketers' Pricing Formats," Journal of Interactive Marketing, Vol. 19, 41-53.

17. Simonson, Itamar (2005), "Determinants of Customers' Responses to Customized Offers: Conceptual Framework and Research Propositions," Journal of Marketing, 69 (January), 32-45. 
NOTES 